\title{
Medical Decision-making and Logics of Negotiation in Living Organ Donation
}

\author{
Natascha Sánchez Hövel \\ Department of Social Anthropology, Complutense University Madrid, Spain
}

Copyright $(2016$ by authors, all rights reserved. Authors agree that this article remains permanently open access under the terms of the Creative Commons Attribution License 4.0 International License

\begin{abstract}
End-stage renal disease requires replacement therapy including renal transplant. Far from being a matter of biomedical criteria or individual choice, the decision whether preferring a dead or a living donor depends on availability. In Spain, cadaveric donation has been the hegemonic practice with an only recent introduction of living donation. The present paper focuses on the logics in the process of decision-making and negotiation between medical professionals and living donors while shaping, developing and giving meaning to an emerging social practice. Concepts of blood, courage, legitimacy and nature are central in the discourse of decision-making inserted in traditional constructions of kinship.
\end{abstract}

Keywords Living Organ Donation, Spanish Model of Coordination and Transplantation, Decision-making, Negotiation, Social Constructions

\section{Introduction}

For decades, Spain has been holding a leading position in organ transplantation being the percentage of cadaveric donation the highest worldwide. The Spanish model of coordination and transplantation has become the flagship of Marca España. The claim of the "world leader in transplantation" is legitimated by statistics that attest the intense transplantation activity and high willingness to donate, in absolute as well as in relative figures. The Spanish case, therefore, presents a singularity in comparison with other countries with similar socioeconomic development and health systems that can be summarized as follows: All the logics and practices that inhabit the transplantation universe, as I call it, are inserted in this hegemonic construction of success and leadership, deriving in challenging realities and conditions for our work as social scientists, as well as in interesting processes of readjustment in the construction of transplantation itself.

Every universe operates with its own common sense and the transplantation universe is no exception. This particular common sense is characterized, on the one hand, by clearly dichotomous logics of good and bad, health and disease, human and machine, life and death, global and local, giving and receiving; logics introduced by the subjects from their experiences prior to their entry in the transplantation universe. These logics coexist and cohabitate, on the other hand, with others that are ambiguous, provisional, uncertain, frightening and changing. The subjects' narratives show processes of subjectivation focused on their effort to bring coherence into the contradictory logics and vanishing frontiers. Biomedicine, and transplantation medicine in particular, goes beyond, blur, dissolve and redefine continuously frontiers and limits known, taken for granted and naturalized in our everyday life. Manzei points out that "crossing, dissolving and removing frontiers does not only produce ambivalence, insecurity and uncertainness, but also provoke and intensify frontier policies and require decisions in order to create new frontiers" [1]. Beck goes even further by pointing out that "the more de-limitation occur, the more decisions are to be taken; this will be characterized by an increase of boundary constructs of provisional morality..." [2]

It is important to emphasize, however, that the ambiguous logics, rules and norms we observe in the transplantation universe do not appear as such but show up in the guise of scientific objectivity. As an example we may think of the isolation measures of transplanted patients. They can be observed as biomedical trends that change over time and vary from place to place; nevertheless they are constructed as an objective scientific truth. And to give another example: When talking of the need and importance of the patient's autonomy- and "celebrating individual choice as an ideal in health care", we often forget what Mol describes as follows: "Mobilizing the logic of choice can lead to poor care. It can shift the weight of everything that goes wrong onto the shoulders of the patient-chooser (...) Choice may be a great ideal but only in situations in which people are indeed able to make their own choices. When they are patients (and I may add: or living donors), people often lack this ability" [3].

The main objectives of the present study are, therefore, (1) to define the fundamental pillars of the construction of 
success creating a very particular transplantation universe, the Spanish in this case, and (2) to identify the ways medical professionals permanently refer to this constructions within their practices when dealing with hegemonic and non-hegemonic logics in a field dominated by apparent objectivity and risk control (lability).

\section{Methods}

In Spain, very few anthropological and ethnographic contributions to the study of organ donation can be observed, and there are even less focusing on living organ donation. The following reflections arise from an ethnographic research project on living kidney donation as an emerging practice in Spain. During 18 months, participant observation was carried out in one of the largest public hospitals in Madrid, including both the pediatric and the general hospital. The face-to-face in-depth interviews took place at the hospital as well as at the university or in a private location of the participant's choosing. Interviews lasted between 60 and 120 minutes and all records were transcribed verbatim.

Participants were recruited according to criteria of theoretical sampling. In order to be eligible, participants had to be either in- or out-patients, potential or real donors, or professionals with direct implication in the donation or transplantation process. Minors of at least 14 years were included with the informed consent signed by one of their parents (there was no case of other legal tutors) and the minor himself or herself. Contact was established at the hospital. Anonymity was preserved.

Access to the field was complicated. Success is constructed in terms of obligation. The hegemonic discourse translates the obligation into the need to increase donation rates by promoting donation, living as well as cadaveric. Social scientists are perceived as critical and could easily compromise the main objective. They are, as well, perceived as strangers in a biomedical domain. Reflecting on these constructions is fundamental in order to understand the dynamics of the field and the practices that emerge in interrelation with -contradictory- logics. Participants in this study were willing and enthusiastic to discuss their perspectives on the topics. However, those who perceived themselves as non-conform to the hegemonic construction demonstrated an important requirement of confidence and anonymity and claimed to be interviewed outside the hospital with an important preference for the university, followed by private locations. This includes patients and donors as well as professionals.

\section{Results}

\subsection{The Keys to Success and Its Consequences}

The primordial condition for a subject's will to donate an organ, either in life or after death, is the existence of a framework of social values that identify this practice as good, correct and natural. Whenever a given society considers one donation modality more natural than other, the first will turn into the dominant practice or, ultimately, in the only one. This process goes together with the development of an appropriate legal framework in order to reinforce its social validity and to legitimate the actions and decisions of the medical professionals. In modern times, public policies and mass media are key in this kind of naturalization processes as "constructors of an institutionalized discourse describing reality (...) by establishing, in the first place, a dominant discourse by means of key channels that excludes alternative categories of thinking and, in the second, creating a legitimate discourse due to the credibility attributed to those channels as disseminators of the objective and official theory" [4]

In this line, we can identify three fundamental pillars that support and create the discourse of Spanish success:

The first and most visible is the construction of the Spanish society as an example of solidarity and altruism in mass media and public policies where the concept of "we are the most altruistic people worldwide" is constantly reproduced and finally echoed by everyday communication within a process of naturalization.

Have faith...everything will be ok... think... there might be good times and bad times, and the good times will give you strength. At least, we are lucky to live in the best country with the best people... willing to donate... and the best medicine you could think of... [Hospital's visitor to a mother of a child on waiting list]

However, the second pillar is considered the most important from the point of view of the professionals. It is the director of the Spanish National Transplant Organization (ONT), Dr. Matesanz, who put it in words:

...social constructions and cultural values have no influence in the quantitative output; not even the potential willingness to donate or not is considered key for the success. What really matters is the efficiency in the coordination of the whole process, the early detection of potential donors in each and every of the intensive care units and the proactive approach in order to obtain the permission of the family and reduce negative responses. [Dr. Matesanz, interview published by the German daily newspaper $\operatorname{taz}[5]$.

The legitimacy of these practices is granted by the third pillar: the legal framework. In 1979, Spain adopted an "opt-out" system according to that organs can be removed from every adult who dies unless a person has registered not to agree. In practice, however, we denominate it a "soft opt-out" since relatives are asked for consent.

However, there are some studies [6] that apparently demonstrate that there is no direct relation between the legal modality and the final donation figures. The analysis of the narratives, indeed, reveals that none of the mentioned pillars is indeed responsible for the success. The driving force that 
sustains and legitimates all practices is the underlying construction of every living or dead being as a potential donor.

I think asking the relatives is a loss of time (..) ... things should be like in Portugal. I don't understand why people won't donate... for what should they need the organs? We must avoid this and force everybody to donate... Asking you waste time... [Father, 59, of an adult son on waiting list]

It is outrageous... she was the perfect donor, really perfect... but her mother meddled in the decision... and you feel like taking apart the mother while asking her: "Lady, your daughter is of full age and wishes to donate and she is the perfect donor... it's not the fault of the guy (the potential recipient and half-brother) that his father married you!" [Nephrologist, 49]

This construction, apparently negotiated, agreed and finally naturalized, turns out to be a biopolitical tool that identifies each and every possible biomedical practice in the transplantation universe as good, correct and natural. Once this biopolitical tool operates, it solves the "dilemma" Scheper-Hughes describes as follows: "The dilemma actually begins ( $\ldots)$, with the first time that one ailing human being looks at another living person and recognizes that inside that other living body is something that could prolong, improve or extend his or her own life" [7]

As a consequence, it could be observed that the feeling of not being taken into account or cared for, or even of being abandoned, is something informants express in many ways: sometimes vehemently, sometimes timidly, sometimes worried since the interview is recorded, sometimes providing names, sometimes referring to specific professional groups. Sometimes the informants generalize but more frequently an attempt to be exact, very exact is found. Sometimes experiences are described as isolated and the informants suggest not to considering them as if they feel not to be authorized to complain while they are lucky to live in Spain.

I have spent half of my life in this hospital and you are the first person to ask me how I am and what have been my experiences. [Female donor, 49]

Well, the whole process has been long and difficult. The most difficult thing was when my son was medically evicted at the age of twelve. The doctor didn't treat us very well, she refused to put him on the waiting list due to his mental deficiency. He was considered a third-class citizen and, therefore, he was not allowed to be on the waiting list, not even with the lowest priority. [Female donor, 65]

I prefer this doctor. The other one should retire... we don't want her to attend us... she used to treat us badly because we are from the Islands. (...) She never addressed us directly. (...) One day, we already had left the consultation room, I heard how she called us "banana trees". [Mother of a donor and grandmother of a recipient]
However, some donors suffer serious health consequences and some loses their work. Although they are very angry and willing to discuss their experiences in the interview, nobody had ever complained.

I would love to share my experience. I'm prepared to make a counter-spot: ... to let everybody know what we do in Spain with living donors... less beating our chest like King Kong... we are the bests... so have a look at this... look what really happens. [Male donor of his son, lost his job after a medical leave of more than a year]

\subsection{Medical Decision-making in Times of Rational Choices}

Donors, nevertheless, are not the only ones left alone in their decision-making. Medical professionals, and especially nephrologists in the present case, are committed with the wellbeing of their patients waiting for a kidney, yet they are also aware of the risks for a living donor; there is unanimity about the fact that if there were an equal alternative to living donation, no medical professional would put in risk a healthy person. Medical protocols establish criteria according to health parameters, social realities, however, remain invisible, disregarded and hazy. As already mentioned, living kidney donation is an emerging and still infrequent modality in Spain, especially when the recipient is not a child or young adult. In our study, we could identify 51 adult patients who have received a kidney from a living related donor since the living donation program had been started. 39 donors were women, 12 were men. On the other hand, only 17 recipients were women and 34 men. Although the present sample is small, the striking gender imbalance is well known in the transplantation universe, in Spain as well as in other biomedically developed countries. However, the gender imbalance is naturalized and taken for granted as a universal human law.

According to Spanish law and practice, and in order to exclude economic interests, a close and lasting relationship between living donor and recipient has to be given before a donor will be accepted. Obviously, this definition includes not only family members but also friends and near colleagues. However, the diversity permitted and intended by law does not at all correspond with the outputs in reality. The types of donor-recipient-relationship are mainly mother/father-child, wife/husband-husband/wife and sister/brother-brother/sister.

In the described study (and in general terms according to national statistics), the vast majority of the donors are mothers and fathers donating to their sons and daughters. In our sample, only $22 \%$ of the donors were not related by blood; this percentage corresponded entirely to married couples; we could not find any not-married couple, neither heterosexual nor homosexual, that was accepted for donation, nor any friends within the donor group. Although there are some cases at the national level, they are still an absolute minority. 
Apart from the lack of diversity, it is important to mention another striking fact on which we easily might be misled. It is the hegemonic biomedical discourse that apparently maintains that a living donor is accepted or refused primarily due to biomedical reasons. Nevertheless, the selection criteria that operate in practice establish a hierarchy of social logics that implicitly guide the biomedical argumentation.

According to this hierarchy we have to start with the biological mother who is considered, in general social terms as well as reflected and shared by donors, recipients and medical professionals, to be the "most legitimate" donor. She once gave birth to her child, and by donating she repeats this act of giving life. According to the rules of gift exchange [8], the -biological- mother is the one with the major right to offer this gift and the child is the one with the major right to receive it for a second time in his or her life. Medical professionals know that mothers do rarely raise any doubts, do not demand any "compensation" from their children and are willing to take important risks for their own lives without complaining when health problems occur after the nephrectomy. The shared assumption that mothers will present the lowest risk of subjective complications is a powerful argument to accept them as donors.

You never need to convince a mother, quite the opposite, you must warn them that they might not be suitable as a donor or that they are too old or not in the necessary conditions. Nevertheless, you tell them to lose weight and they do it. You can be very sure that they will do everything. [Nephrologist, 49]

You know... being a mother is painful. That's life... to give birth means pain and to be a mother means pain, as well. [Female donor, 49]

When everything was prepared, the doctor gave me a booklet and told me to read and sign it, and to enter again when I felt prepared. My sister-in-law and I left the room and we had a look at it... and I was horrified. When we entered again, I told my sister-in-law: "We didn't read it! You ought to forget it... I will forget it!" If you are sure of what to do, you don't need any information. [Female donor, 73]

Whereas mothers donate in any possible moment, preferably in an early stage in order to avoid dialysis, the decision-making for fathers seems to take some more time and to be much clearer when the child already needs dialysis and the suffering is more visible. Other important differences that could be observed are the higher prevalence of reported health problems after the nephrectomy as well as the existence of an underlying construction of success and demand. Fathers frequently consider the act of donation as a kind of "investment" in their children's future and demand a "responsible style of life", or even "academic and professional excellence". These expectations can origin conflicts and create vulnerability when faced with failure, real or future.

I didn't accept to do it via laparoscopy... in spite of the surgeons' insistence. But if my son loses the kidney, it would be a shock. Ok, you can always say: "I did what I could." I'm a person who needs to feel the satisfaction of doing what must be done. But in this case, to do what must be done, is secondary, the priority is to assure the optimum survival of the graft. It would have been disappointing... So, I went for open surgery, refusing laparoscopy. [Male donor, 57]

Both medical professionals as well as -male and femaledonors prioritize women instead of men as donors; the social construction of women as natural caregiver is overwhelming. Women construct themselves -and are constructed- as "strong, determined and brave"; native terms that appear frequently in the testimonies.

I have always been very brave. I do things because somebody has to do them and because I know I can do them. If others had to do them, things kept undone. [Female donor, 49]

The decision is mine. I have always had a lot of courage, a lot of strength. And I want my son to live. [Female donor, 65]

I told everybody: "I am absolutely sure that everything will go well. I won't allow things going wrong." And everybody called me brave or courageous. [Female donor, 73]

I had to continue taking care of my son, preparing meals, cleaning the house, and taking care of my husband who felt exhausted just because of escorting us to hospital... [Female donor, 49]

Therefore it does not surprise that the natural donor in common sense terms is a blood-related female. As we already mentioned, this common sense circulates within the transplantation universe and is shared not only by patients, donors and other non-experts, but its logics are naturalized, as well, by the medical professionals. The more theses criteria are met, the more solid and legitimate is considered the right to donate. On the opposite end of our invisible axis of good versus bad donors we could, therefore, find a non-blood-related male who would be constructed as "of no use" or "a risky choice".

It is not that easy. The doctor told me not to donate, to think of my children, my job, to remember that my friend can continue with dialysis... he will be ok... and there are a lot of family members who could to it. It is not that easy like it's being sold. [Boyhood friend, 39 , of a patient on waiting list]

Every potential donor who presents himself or is presented as such will immediately -and unconsciously- be placed on some point of that axis. Although this placing goes unnoticed, the initial position is a reliable indicator of the final result due to the power of shared social constructions.

I love my brother, really, but I can very much 
understand that people refuse donating to their brother... honestly, I wouldn't do it either... not to a brother... and it's not because being a doctor or not... or knowing how things work... [Nephrologist, 43]

Medical protocols and the legal framework, nevertheless, refer to criteria different of those mentioned. When a donor is introduced, nephrologists usually would start with checking the -biochemical- compatibility and continue by examining the health of the future donor. Apparently, these steps do not include any social dimension. In equal conditions, a male donor would be preferred due to a higher kidney volume, however this point is considered of minor importance and rarely ever up for discussion. Compatibility and health conditions, however, are very much negotiated between donors and medical professionals in order to regain the initially occupied position on our invisible axis. With the exception of "objective" biological impossibility (e.g. kidney abnormality), determined female donors try to convince of their good or, at least, acceptable health conditions. Health conditions are complex, difficult to compare and much more subjective than biomedicine would admit, so a donor might persuade by firm intention, courage, endurance and sense of responsibility. This is even the case when compatibility is not at all ideal; mothers with a different blood group than their children are not likely to give up but frequently demand a relatively recent -and expensiveblood treatment (desensitization) to make her compatible with the recipient. Whenever economic resources are available and the risk for the donor seems to be acceptable, medical professionals share the social construction of the hierarchy of ideal -and natural- donors and choose a blood-related "brave" female disregarding even poor compatibility.

Even more striking than the process of acceptance is the one of denial. A series of underlying stereotypes could be observed that are activated in the case of donors that, according to the just mentioned logics, would be considered far from being ideal or natural. Whenever the type of bond between the donor and the recipient defies hegemonic logics, prejudices are activated in order to categorize the different types of donors according to their relationship. In other words, whenever the bond between donor and recipient is endowed with ambiguous o negative meaning, the donor will be constructed according to this meaning predetermining the attitude towards him or her. Although the underlying logics are visible and socially constructed, the argumentation by the professionals is formulated in biomedical terms. In the case of homosexual male couples, the discourse easily refers to "typically homosexual risk practices" and a therefore higher risk of HIV/Hepatitis, although the blood testing would be negative.

I wouldn't be surprised... we once had a gay recipient... now he's in jail and doesn't even take his cyclopsporine. The risk is always higher... you always have to keep a close eye... [Nephrologist, 43]

Homosexual female couples are frequently constructed as "quarrelsome", "critical" and "excessively determined".
They, as well, seem to lack a sense of responsibility defined as the high readiness to fulfill medical mandates.

She's also a vegetarian... it's even a struggle to convince her to take her vitamins... She discusses any issue twice... She knows everything better. And her "friend" is identical. We will keep her on waiting list... dialysis will teach her being more collaborative... [Nephrologist, 43]

The importance of compliance and adherence is, with no doubt, crucial in post-transplantation treatment, however, the construction of an implicit relationship between non-hegemonic life-styles, sexual orientation or other behavior and compliance and adherence is based on non-reflected- stereotypes that are consequently legitimated in biomedical terms.

\section{Discussion}

We can affirm that the success construction has wide-ranging consequences for the practices and logics that inhabit this particular transplantation universe. In the first place, we observe that ethical or moral objection or doubts that may arise are turned down and silenced in order not to endanger the transplant activity figures as the key indicator of success. The "provisional morality", Beck refers to, is rapidly and unfiltered elevated to "absolute and true morality", legitimating all biomedical practices in the transplantation universe to the detriment of ethical and transparent procedures. Public recognition and prestigious awards, like the Prince of Asturias Award for the ONT in 2010, operate as reinforcement of this legitimation. Second, due to the lack of critical discussions, the right to obtain medical treatment, assistance and care, is easily confused with the right to receive the organ of another person. Whenever this right is perceived -socially and individuallyas legitimate and natural, the act of donation loses its voluntary character and every potential living -relateddonor will feel, and suffer, this moral obligation when trying to take a decision.

The fact that the decision-making takes place in a universe dominated by a success construction makes it even worse for the donor, yet the donation is promoted as if it did not bear any risk for the donor. The figures seem to prove that Spain is -apparently- the safest place on earth when dealing with transplantation, yet psycho-social risks are neither considered nor investigated. The awareness of the fact that stagnation would put in danger the success has led to important efforts in terms of promotion. Therefore, when waiting lists started to grow, living donation -more exactly living kidney donation- was introduced; however its promotion has been anchored in the hegemonic construction of altruism and solidarity, taking for granted that the reasons and motivations for permitting the donation from a dead next-of-kin were the same as those when deciding to become a living donor; which we could demonstrate is not the case and could mean serious risks for living donation practices. 
The image of living donation as the best option for the recipient and as "safe and gratifying" for the donor was created and has been managed with very few ethical qualms and even less knowledge. This image is biomedically as well as socially wrong: Biomedically, as far as it is not the transplantation modality (living or cadaveric donation) but the time the patient has spent in dialysis that makes the difference. Socially, because it can never be assured that an experience is gratifying, neither in the short nor in the long term. To do so is far from being an ethical practice. And finally "safe" is nothing but a statistically calculation involving a double surgery on a patient and on a healthy person.

Whereas ideal donors in social terms, like biological mothers, receive a minimum of biomedical protection due to their low potential for conflict, being especially vulnerable in case of serious problems, donors who are perceived as conflictive due to their model of relationship, life-style or sexual orientation are "over-protected" due to a supposed vulnerability. This over-protection is coherent with a biomedical and psychological logic of healthy, beneficial and "normal" behavior and leads to the activation of protecting individuals with assumed non-healthy or non-beneficial or non-hegemonic behavior from the consequences of their own behavior. In other words, biomedical practice operates in terms of biopower in order to reestablish the social order revealed by the common sense.

\section{Conclusions}

At the whole, we can conclude that living kidney donation in Spain is an emerging practice that provides evidence of the underlying social logics that operate in the process of decision-making. Whereas donor selection and acceptance is constructed as a biomedical criteria based process, the invisible and naturalized but shared social constructions on good and natural donors versus bad and unnatural ones are, nevertheless, the dominant criteria.

Medical professionals, as participants of the shared common sense, however, are only in part aware of their stereotypes and frequently mask it with "objective" biomedical reasons. The complexity of these processes, however, remains invisible and turns living donation into an unknown and risky social practice in spite of the fact that it is socially and publicly constructed as a safe, favorable and well-known practice promoted by public authorities, patients associations and the pharmaceutical industry demonstrating an important lack of responsibility. Non-awareness produces, nevertheless, different forms of vulnerability that will be exacerbated by the increase of living donation. Therefore, the right to learn everything about the possible consequences and experiences, to reflect on the actual practices and the implicit stereotypes, to give or receive a committed care and attention, to empower donors as well as medical professional, has to be a priority within the responsible promotion of living donation.

\section{REFERENCES}

[1] A. Manzei, W. Transplantationsmedizin. Kulturelles Wissen und gesellschaftliche Praxis. Agenda Verlag, Münster, 2006.

[2] U. Beck, W. Bonß, C. Lau. Entgrenzung und Entscheidung: Was ist neu an der Theorie reflexiver Modernisierung. Suhrkamp, Frankfurt, 2004

[3] A. Mol. The logic of Care. Health and the problem of patient choice. Rotledge, New York, 2008.

[4] B. Agrela Romero. De los significados de género e inmigración (re)producidos en las políticas sociales y sus consecuencias para la acción e integración social. In: L. Cachón, M. Laparra (comps.) Inmigración y Políticas Sociales. Bellaterra, Barcelona, 2006.

[5] TAZ-Interview, July 9th, 2013 ("Dieser Moment am Lebensende")

[6] Online available: http://www.odt.nhs.uk/pdf/the-potentialimpact-of-an-opt-out-system-for-organ-donation-in-the-UK. pdf

[7] N. Scheper-Hughes. Parts unknown: Undercover ethnography of the organ-trafficking underworld. Ethnography 5, no. 1, $29-73$

[8] N. Sánchez Hövel. La donación de vivo en el trasplante renal. Entre el regalo de vida y la tiranía del regalo. Anales de la Fundación Joaquín Costa, 28, 165-190 